\title{
Incorporation of Fuzzy Logic to the Black-Scholes Model in Exchange Option Pricing
}

\author{
Manuel Muñoz Palma', Ezequiel Avilés Ochoa ${ }^{1}$ \\ ${ }^{1}$ Universidad de Occidente, Culiacan, Mexico \\ mpalma25@hotmail.com, eaviles8a@hotmail.com
}

\begin{abstract}
Since the introduction of the uncertainty theory, a new paradigm in economy and finance is formed with the incorporation of new models that allow a greater degree of accuracy to the reality of the environment of organizations based on the fuzzy logic theory. This article emphasizes the importance of the uncertainty present in the financial markets, which has provoked an increasing need of establishing models to determine its effect in pricing, as it is the case of the futures and derivatives markets. A proposal is developed to determine the price of an exchange option applying triangular fuzzy numbers to exchange rate variables, and to domestic interest rates, and foreign interest rates based on the classic Black-Scholes (B-S) model.
\end{abstract}

Key words: Financial risk, fuzzy numbers, Black-Scholes model.

\section{Introduction}

The current problems in the field of option pricing are characterized by uncertainty. "The Black-Sholes Model introduced in 1973, has always been the cornerstone of option pricing, however, generic applications of this model are limited by nature of not being suitable for fuzzy environments in decision-making"(Lee, Tzeng \& Wang, 2005).

When an investor or organization is faced with an option pricing problem, the results of the primary variables depend on the investor's estimate. This means that the individual or individuals' deduction and their thought processes correspond to the non-binary logic with fuzziness. Since the techniques provided by the theories of probability are not sufficiently suitable to quantify such fuzziness, doing so would imply the acceptance that fuzzy events are equivalent to random events. On the other hand, fuzzy logic allows formalizing the fuzziness of phenomena by means of an assignment of a characteristic function in which there is a degree between absolute belonging and not belonging. Therefore, while probability is associated to randomness, the membership function is associated to the lack of clarity; however, it is important to mention that both concepts have a common point since both are included between zero and one.

When determining the price of an option, the organization usually depends on an expert's judgment to obtain the probability distribution of primary variables in the B$\mathrm{S}$ model. When assessing the distribution of the variables, the expert evaluates the influence of the sample information, which involves the subjective judgment of the expert, that is, the fuzzy factor. However, "the B-S model does not consider the expert fuzzy factors in the price of an option." (Lee, Tzeng \& Wang, 2005).

\section{Fuzzy Logic and the Black-Scholes Model}

In most of the phenomena analyzed, a degree of inaccuracy can be found, that is, they implicitly have a certain degree of uncertainty in the description of their nature; it is the inaccuracy associated with its shape, position, texture, color, or the semantics used to describe what they are. Even a concept can establish different degrees of inaccuracy in different contexts or at different times. As stated by Kaufmann \& Gil-Aluja (1986), "the new treatment of uncertainty, from the fuzzy concepts, has led to a different way of thinking that meet the rigorous sequential reasoning wealth of imagination inherent in blurring, partnering opportunities sequential machine to the possibilities of human brain".

At the present time, there are studies in the field of fuzzy logic in finance such as the one developed by Bart Kosko (1986), who formulated the "Fuzzy Entropy Theorem" and which allows to measure the fuzziness of a fuzzy subset. In 1990, the economist Gil-Aluja proposed the principle of gradual simultaneity, in which any sentence can be true or false at the same time on the condition that it assigns a degree to the truth and one to the false. For this reason, the human factor is an inherent element in the decision-making of "rationally nuanced" organizations, giving rise to fuzzy mathematics of uncertainty and a range of applications in science including economy and finance. 


\subsection{Fuzzy Logic}

The definitions in the fuzzy sets are clear extensions corresponding to the ordinary sets. Zadeh (1965:340) mentions the following:

1. A fuzzy set is empty if and only if its membership function is identically zero on $X$.

2. Two fuzzy sets $A$ and $B$ are equal if and only if:

$$
f_{A}(x)=f_{B}(x) \text { for all } x \text { in } X\left(f_{A}=f_{B}\right)
$$

3. The complement of a fuzzy set $A$ is written as $A^{\prime}$ and defined by:

$$
f_{A^{\prime}}=1-f_{A}
$$

4. Containment, $A$ is contained in $B$ (or equivalently, $A$ is a subset of $B$, or $A$ is smaller or equal to $B$ ) if and only if:

$$
f_{A} \leq f_{B}
$$

Equally, in symbols:

$$
A \subset B \leftrightarrow f_{A} \leq f_{B}
$$

5. The union of two fuzzy sets $A$ and $B$ with their respective membership functions $f_{A}(x)$ and $f_{B}(x)$ is a fuzzy set $C$, written as $C=A \cup B$, whose membership function is related to the ones of $A$ y $B$, for what:

$$
f_{C}(x)=\operatorname{Max}\left[f_{A}(x), f_{B}(x)\right], \quad x \in X
$$

Or, in abbreviated form can be written as:

$$
f_{C}=f_{A} \vee f_{B}
$$

6. The intersection of two fuzzy sets $A$ and $B$ with their respective membership functions $f_{A}(x)$ and $f_{B}(x)$ in a fuzzy set $C$, written as $C=A \cap B$, whose membership function is related to $A$ and $B$ by:

$$
f_{C}(x)=\operatorname{Min}\left[f_{A}(x), f_{B}(x)\right], x \in X
$$

Or, in abbreviated form, written as:

$$
f_{C}=f_{A} \wedge f_{B}
$$

\subsection{The application of fuzzy logic to finance}

In the financial management area, numerical precision has traditionally been used; however, nowadays, progress has turned economic environment uncertain. Hence, a need arises to "build a theory of fuzzy numbers to allow a quantification of an actual phenomenology more in line with the structure of human thought" ( Kaufmann \& GilAluja, 1986).

Fuzzy numbers are defined as a fuzzy subset of reference to the real numbers that has a normal membership function, where $x$ should exist, for which $\mu(x)$ takes the value of one and convexes, and where any spread to the right or left of value $x, \mu(x)$ decreases. The fuzzy numbers theory can be considered as an extension of the confidence interval theory when all levels from 0 to 1 in the intervals are considered, instead of considering one single level.

A fuzzy number is formed with a finite or infinite sequence of confidence intervals with the following characteristics:

- Level of presumption, if:

$$
\alpha \in(0,1)
$$

- $A_{\alpha}=\left[a_{1}{ }^{\alpha}, a_{2}{ }^{\alpha}\right\rfloor$ is defined as the confidence interval of level $\alpha$, which must satisfy:

$\left(\alpha^{\prime}<\alpha\right) \rightarrow\left(A_{\alpha} \supset A_{\alpha^{\prime}}\right), \quad \alpha, \alpha^{\prime} \in[0,1]$

- Only one interval and only one can be reduced to a single real number.

- A fuzzy number is represented by a capital letter and with a symbol below it $\left(A_{\sim}\right)$.

- The confidence interval of level $\alpha$ is defined as $A_{\alpha}$, also known as " $\alpha-$ cut of $A$ ”; which can be written in the following manner:

$$
\begin{aligned}
& \mu_{A \alpha}(x)=1 \text { if } x \in\left[a_{1}(\alpha), a_{2}(\alpha)\right] \\
& \mu_{A \alpha}(x)=0 \text { if } x \notin\left[a_{1}(\alpha), a_{2}(\alpha)\right]
\end{aligned}
$$

In fuzzy numbers, the most used characteristic functions for their mathematic simplicity are triangular, trapezoidal, Gaussian, and sigmoid. There are two approaches to determine the characteristic function: the first approach is based on the human knowledge of experts and the second one is to use a data collection to design the function. 
Due to its easiness to use, the triangular fuzzy number (TFN) is determined by three quantities: one that is the lowest possibility, another which is the highest possibility, and one that represents the maximum level of presumption (Kaufmann \& Gil-Aluja, 1987). The membership function $\mu$ is linear, expressed by three numbers $\left(a_{1}, a_{2}, a_{3}\right)$ and represented as follows:

$$
\underset{\sim}{A}=\left(a_{1}, a_{2}, a_{3}\right)
$$

Where:

$$
\begin{aligned}
& a_{1}, a_{2}, a_{3} \in R \\
& a_{1} \leq a_{2} \leq a_{3}
\end{aligned}
$$

The graphic representation of the triangular fuzzy number $\left(a_{1}, a_{2}, a_{3}\right)$ is shown in the following figure:

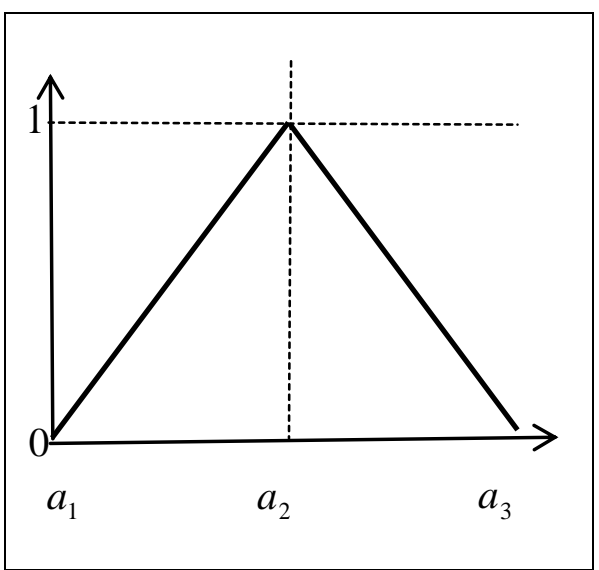

Figure 1. Graphic representation of a triangular fuzzy number. Source: Kaufmann y Gil-Aluja, 1987.

As shown in Figure 1, TFNs are distinguished because their level of presumption equals to 1 for the central value and it equals to 0 for the lower and upper ends. The level of presumption gains importance in the different applications. According to Gil-Aluja (2004), the membership function is defined as follows:

$$
\mu_{A(x)}=\left\{\begin{array}{rcc}
0 ; & \text { if } & x \leq a_{1} \\
\frac{x-a_{1}}{a_{2}-a_{1}} ; & \text { if } & a_{1}<x \leq a_{2} \\
\frac{a_{3}-x}{a_{3}-a_{2}} ; & \text { if } & a_{2}<x \leq a_{3} \\
0 ; & \text { if } & a_{3} \leq x
\end{array}\right.
$$

The general expression for $\alpha-c u t$, solving for $x$, in terms of the presumption level:

$$
\alpha=\mu_{A(x)}
$$

For the lower end

$$
\alpha=\frac{x-a_{1}}{a_{2}-a_{1}} \rightarrow x=a_{1}+\alpha\left(a_{2}-a_{1}\right)
$$

For the upper end

$$
\alpha=\frac{a_{3}-x}{a_{3}-a_{2}} \rightarrow x=a_{3}-\alpha\left(a_{3}-a_{2}\right)
$$

Being $\alpha$-cut:

$$
\forall \alpha \in[0,1]
$$

$$
A \alpha=\left[a_{1}+\alpha\left(a_{2}-a_{1}\right), a_{3}-\alpha\left(a_{3}-a_{2}\right)\right]
$$

With the TFNs, the same operations are done as the ones done with the ordinal real numbers, such as addition, subtraction, multiplication, division, and others. Therefore, TFNs help determine, in a credible manner, a great number of situations of the economic entity in which localized magnitudes are estimated in the future. Based on this, it is important to mention that in the area of economy and finance, problems whose magnitudes are projected to the future are studied and although they do not demand extreme accuracy, they do require a greater adaptation to reality.

\section{Analysis of fuzzification of variables.}

\subsection{Analysis of the effect of fuzzification of the ex- change rate variable for the March 2009 to March 2011 period.}

In this section, the importance of fuzzy logic in the field of economy and finance is emphasized. The advancement in technology, the market diversity, the multiplicity and variety of products have created a greater need for businessman intuition to be fulfilled with increasingly more complex models. The possibilities offered by fuzzy subsets to face such decision-making problems in the area of entrepreneurial action are increasingly broader to enhance financial management. As stated by Gil-Aluja (2004), "classical models based on data accuracy could be ineffective when reality will not allow achieving it; therefore, if this information is not available, it is necessary to use subjective numerical calculations called valuations."

The Black-Scholes model developed in 1973 by Fischer Black and Myron Scholes is a tool generally used to determine option pricing in the derivatives market in most 
countries. It allows determining the future pricing of an option for different hedge instruments, options, futures, swaps, and warrants. According to Kaufmann \& GilAluja (1986), the incursion of fuzzy logic in every variable by means of the triangular fuzzy number (TFN) enables the establishment of a triplet and calculates the endecadaria scale. In this study, the characteristic function to be used is the triangular one, which is determined by using the approach based on expert human knowledge. For such, the set number of experts is four (4); the forecast with Fisher's theory variables is considered for expert 1 , the forecast with PPA variables for expert 2 , the forecast with balance of payments variables for expert 3 , and forecast of trend analysis with one variable for expert 4. Also, time series econometrics operations were carried out using the Winters \& ARIMA models through the Minitab Statistical Software to forecast the exchange rate variables, as well as the domestic and foreign interest rate variables. The forecast is determined based on the data obtained during the 2006 to 2009 period and from which the following confidence triplets were obtained:

Table 1. Confidence triplet exchange rate for March 2009

\begin{tabular}{|c|c|c|c|}
\hline EXPERT & $\mathrm{A}_{1}$ & $\mathrm{~A}_{2}$ & $\mathrm{~A}_{3}$ \\
\hline 1 & 13.711200 & 13.83960 & 14.00330 \\
\hline 2 & 13.527000 & 14.00330 & 14.47900 \\
\hline 3 & 11.863100 & 13.22620 & 14.58930 \\
\hline 4 & 13.516800 & 13.73670 & 13.95670 \\
\hline & & & \\
\hline TFN & 13.15453 & 13.70145 & 14.24825 \\
\hline
\end{tabular}

Source: Author's calculations based on Banxico's data.

As shown in Table 1, the option (forecast) of every expert is written in a triangular fuzzy number, as well as the average fuzzy number, or aggregate, which is the result of adding the three columns and divides the result by the number of experts. According to Gil-Aluja (2004), it is expressed as follows:

$$
T=\left(\begin{array}{c}
m \\
A_{1}+A_{2}+A_{3}
\end{array}\right)
$$

Given the opinion of the experts, it is assumed that the expected exchange rate for March 2009 is defined by the TFN (13.15453, 13.70145, 14.24825), which indicates that the predicted exchange rate is between 13.15453 and 14.24825 , being 13.70145 the value with the greatest possibility of occurrence. From this expression and the aggregated triangular fuzzy number (13.15453, 13.70145, 14.24825), $\alpha$ values are assigned according to the endecadaria scale in $[0,1]$. For which we have the following:
Table 2. Level of presumption for the exchange rate for March 2009

\begin{tabular}{|c|c|c|}
\hline $\boldsymbol{\alpha}$-corte & $\mathbf{a}+\boldsymbol{\alpha}(\mathbf{a}-\mathbf{a})$ & $\mathbf{a}-\boldsymbol{\alpha}(\mathbf{a}-\mathbf{a})$ \\
\hline 0 & 13.15453 & 14.24825 \\
\hline 0.1 & 13.20922 & 14.19357 \\
\hline 0.2 & 13.26391 & 14.13889 \\
\hline 0.3 & 13.31860 & 14.08421 \\
\hline 0.4 & 13.37330 & 14.02953 \\
\hline 0.5 & 13.42799 & 13.97485 \\
\hline 0.6 & 13.48268 & 13.92017 \\
\hline 0.7 & 13.53737 & 13.86549 \\
\hline 0.8 & 13.59207 & 13.81081 \\
\hline 0.9 & 13.64676 & 13.75613 \\
\hline 1 & 13.70145 & 13.70145 \\
\hline
\end{tabular}

Source: Author's own production.

Based on the previous information, the different exchange rate confidence intervals and levels of presumption are obtained for March 2009. The exchange rate can take any value included in the interval of reference and all values have a determined level of presumption associated to them. In the following figure it can be seen that the fuzzy number that represents the exchange rate is in fact a TFN, since it satisfies their convexity properties.

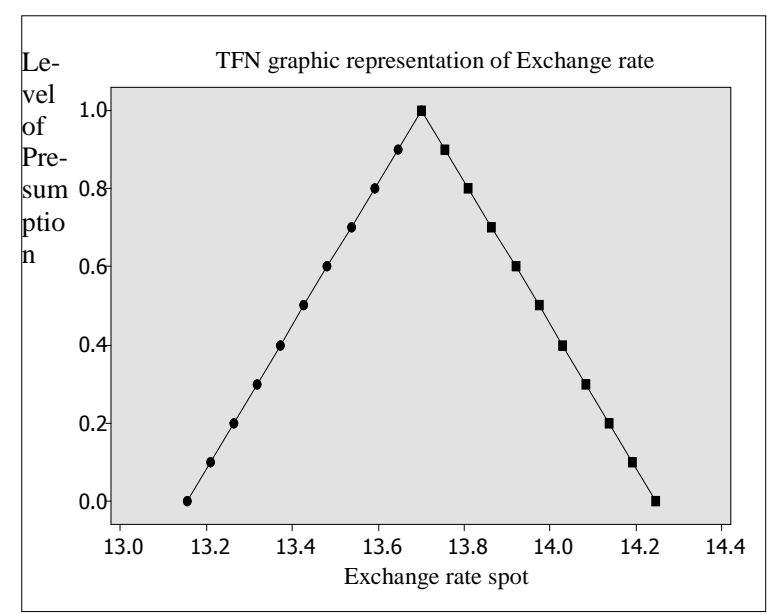

Figure 2. Graphic representation of TFN exchange rate for March 2009.

Source: Author's own production.

For the June 2009 to March 2011 period, the same procedure is carried out which was determined for each of the periods that were analyzed.

\subsection{Analysis of the effect of fuzzification of the CETES (Mexican Federal Treasury Certificates) rate variable for the March 2009 to March 2011 period.}

For the CETES (Mexican Federal Treasury Certificates), the experts are defined by the time series forecasting models. For expert 1, the Winters' forecasting model is considered; for expert 2, the forecasting is based on the ARIMA model; for expert 3 , the forecasting is based on 
the moving average model; and for expert 4, forecasting is based on trend analysis with one variable using the Minitab Software. The forecast is determined based on the data obtained during the 2006 to 2009 period and from which the following confidence triplets were obtained:

Table 3. Confidence triplet of CETES rate for March 2009

\begin{tabular}{|c|c|c|c|}
\hline EXPERT & $\mathrm{A}_{1}$ & $\mathrm{~A}_{2}$ & $\mathrm{~A}_{3}$ \\
\hline 1 & $7.66567 \%$ & $7.92553 \%$ & $8.18539 \%$ \\
\hline 2 & $6.93990 \%$ & $7.11056 \%$ & $7.28121 \%$ \\
\hline 3 & $7.05418 \%$ & $7.13750 \%$ & $7.22082 \%$ \\
\hline 4 & $5.80962 \%$ & $5.90255 \%$ & $6.99950 \%$ \\
\hline & & & \\
\hline TFN & $6.86734 \%$ & $7.01904 \%$ & $7.42173 \%$ \\
\hline
\end{tabular}

Source: Author's own production based on Banxico's data.

It is assumed that the expected CETES rate for March 2009 is defined by the aggregated TFN (6.86734\%, $7.01904 \%, 7.42173 \%)$. That is, the CETES rate is between $6.86734 \%$ and $7.42173 \%$, being $7.01904 \%$ the value with the greatest possibility of occurrence. There is a greater impact in this period due to the volatility of the international markets since there was an increase in the interest rate.

From the $a-c u t$ expression and the aggregated TFN $(6.86734 \%, 7.01904 \%, 7.42173 \%)$, values are assigned to $\alpha$ according to the endecadaria scale in $[0,1]$. For which we will have the following:

Table 4. Level of presumption for CETES rate for March 2009

\begin{tabular}{|c|c|c|}
\hline $\boldsymbol{\alpha}$-corte & $\mathbf{a}+\boldsymbol{\alpha}(\mathbf{a}-\mathbf{a})$ & $\mathbf{a}-\boldsymbol{\alpha}(\mathbf{a}-\mathbf{a})$ \\
\hline 0 & $6.8673 \%$ & $7.4217 \%$ \\
\hline 0.1 & $6.8825 \%$ & $7.3815 \%$ \\
\hline 0.2 & $6.8977 \%$ & $7.3412 \%$ \\
\hline 0.3 & $6.9129 \%$ & $7.3009 \%$ \\
\hline 0.4 & $6.9280 \%$ & $7.2607 \%$ \\
\hline 0.5 & $6.9432 \%$ & $7.2204 \%$ \\
\hline 0.6 & $6.9584 \%$ & $7.1801 \%$ \\
\hline 0.7 & $6.9735 \%$ & $7.1398 \%$ \\
\hline 0.8 & $6.9887 \%$ & $7.0996 \%$ \\
\hline 0.9 & $7.0039 \%$ & $7.0593 \%$ \\
\hline 1 & $7.0190 \%$ & $7.0190 \%$ \\
\hline
\end{tabular}

Source: Author's own production.

Given this information, different CETES rate confidence intervals and different levels of presumption are obtained for March of 2009, shown in the following graphic:

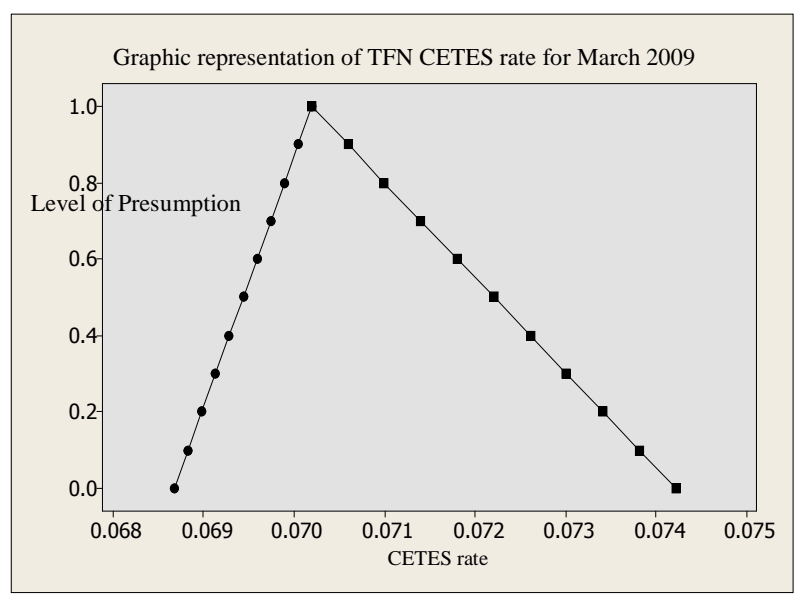

Figure 3. Graphic representation of CETES rate TFN for March 2009.

Source: Author's own production.

For which the same technique was determined for each of the trimestral periods from June 2009 to March 2011 for the B-S calculation.

\subsection{Analysis of the effect of fuzzification of the varia- ble T-bill rate for the March 2009 to March 2011 peri- od.}

In the T-bill rate for March of 2009, the experts are defined by the time series forecasting models. For expert 1 , the Winters' forecasting model is considered; for expert 2, the forecasting is based on the ARIMA model; for expert 3 , the forecasting is based on the moving average model; and for expert 4 , forecasting based on trend analysis with one variable using the Minitab Software. The forecast is determined based on the data obtained during the 2006 to 2009 period and from which the following confidence triplets were obtained:

Table 5. Confidence triplet of the T-bill rate for March 2009

\begin{tabular}{|c|c|c|c|}
\hline EXPERT & $\mathrm{A}_{1}$ & $\mathrm{~A}_{2}$ & $\mathrm{~A}_{3}$ \\
\hline 1 & $0.042390 \%$ & $0.184557 \%$ & $0.326724 \%$ \\
\hline 2 & $0.104873 \%$ & $0.147500 \%$ & $0.191027 \%$ \\
\hline 3 & $0.001942 \%$ & $0.158326 \%$ & $0.314709 \%$ \\
\hline 4 & $0.013712 \%$ & $0.232900 \%$ & $0.282900 \%$ \\
\hline & & & \\
\hline TFN & $0.040730 \%$ & $0.180820 \%$ & $0.278840 \%$ \\
\hline
\end{tabular}

Source: Author's own production based on Banxico's data.

According to the previous information, it is assumed that the expected T-bill rate for March 2009 is defined by the aggregated TFN $(0.04073 \%, 0.18082 \%, 0.27887 \%)$. It can be observed that the interest rates are very low due to the policies established by the U.S. Federal Reserve caused by the financial crisis of the subprime mortgage loans. 
From the $a-c u t$ expression and the aggregated TFN $(0.04073 \%, 0.18082 \%, 0.27884 \%)$, values are assigned to $\alpha$ according to the endecadaria scale in $[0,1]$. For which we have the following:

Table 6. Level of presumption for the T-bill rate, March 2009

\begin{tabular}{|c|c|c|}
\hline $\boldsymbol{\alpha}$-corte & $\mathbf{a}+\boldsymbol{\alpha}(\mathbf{a}-\mathbf{a})$ & $\mathbf{a}-\boldsymbol{\alpha}(\mathbf{a}-\mathbf{a})$ \\
\hline 0 & $0.04073 \%$ & $0.27884 \%$ \\
\hline 0.1 & $0.05474 \%$ & $0.26904 \%$ \\
\hline 0.2 & $0.06875 \%$ & $0.25924 \%$ \\
\hline 0.3 & $0.08276 \%$ & $0.24943 \%$ \\
\hline 0.4 & $0.09677 \%$ & $0.23963 \%$ \\
\hline 0.5 & $0.11077 \%$ & $0.22983 \%$ \\
\hline 0.6 & $0.12478 \%$ & $0.22003 \%$ \\
\hline 0.7 & $0.13879 \%$ & $0.21023 \%$ \\
\hline 0.8 & $0.15280 \%$ & $0.20042 \%$ \\
\hline 0.9 & $0.16681 \%$ & $0.19062 \%$ \\
\hline 1 & $0.18082 \%$ & $0.18082 \%$ \\
\hline
\end{tabular}

Source: Author's own production.

The T-bill rate variable can take any value within the reference interval and every value has a determined level of presumption associated to it. In this manner, it can be established that the forecast of the T-bill rate using forecasting time series is between 0.04073 and $0.18082 \%$, being $0.27884 \%$ the presumed maximum value. The following figure shows how the level of presumption increases linearly from the bottom end $(0.040735 \%)$ to the highest possible value $(0.27884 \%)$ and decreases linearly from this value to the upper end $(0.18082 \%)$

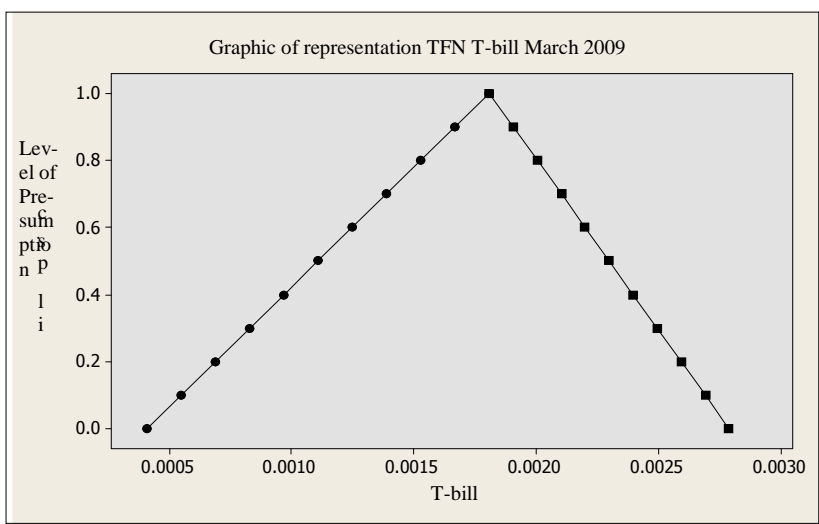

Figure 4. Graphic representation of the T-bill rate for March 2009.

Source: Author's own production.

The same procedure is followed for the June 2009 to March 2011 period.

\section{Results of the application of the triangular method (TFN) to the Black-Scholes (BS) model.}

Based on the data obtained with the fuzzification of the exchange rate variables, the domestic interest rates, and the foreign interest rates for the period of March 2009 to March 2011, calculations are carried out to determine the price of the option for the traditional B-S model and the B-S with the fuzzification of the variables based on the following formula:

$$
\begin{gathered}
C=S e^{-R t} N\left(d_{1}\right)-K e^{-r t} N\left(d_{2}\right) \\
d_{1}=\frac{\ln \left(\frac{S}{K}\right)+\left(r-R+0.5 \sigma^{2}\right) t}{\sigma \sqrt{t}} \\
d_{2}=d_{1}-\sigma \sqrt{t}
\end{gathered}
$$

Where:

$C=$ Call option value

$S=$ Exchange rate.

$K=$ Option strike price.

$r=$ Domestic interest rate.

$R=$ Foreign interest rate.

$\sigma=$ Standard deviation of daily return for spot exchange rate.

$e=$ Base of the Napierian logarithm (2.7182).

$\ln =$ Napierian logarithm.

$N\left(d_{1}\right)$ y $N\left(d_{2}\right)=$ Area under the standard normal distribution curve.

From the above, the following results for the level of maximum presumption are obtained:

Table 7. Results obtained from the level of maximum presumption

\begin{tabular}{|c|c|c|c|}
\hline PERIOD & $\begin{array}{c}\text { B-S THEORE- } \\
\text { TICAL }\end{array}$ & $\begin{array}{c}\text { DERIVATIVES } \\
\text { MARKET }\end{array}$ & $\begin{array}{c}\text { B-S FUZZIFICA- } \\
\text { TION VARIABLES }\end{array}$ \\
\hline March-01-2009 & 0.21502 & 1.13200 & 0.30833 \\
\hline June-01-2009 & 0.42840 & 1.51000 & 0.67886 \\
\hline March-01-2010 & 0.14275 & 0.90400 & 0.15643 \\
\hline June-01-2010 & 0.10905 & 0.36000 & 0.15468 \\
\hline March-01-2011 & 0.13369 & 0.32300 & 0.26730 \\
\hline
\end{tabular}

Source: Author's own production.

When analyzing the obtained values, it can be observed that based on the fuzzification of the variables involved in determining an option, it is possible to decrease the degree of uncertainty present in the MexDer and the traditional B-S model, as shown in the next chart: 


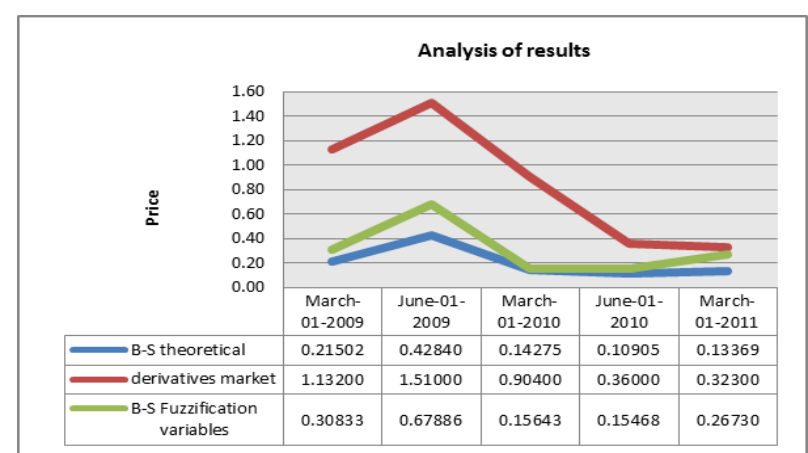

Figure 5. Comparison of the price of an exchange option in the level of maximum presumption.

Source: Author's own production.

The chart shows a significant increase in the price of a premium in 2009 caused by the high volatility of the financial markets, as well as the 2008 mortgage crisis in the United States. Beginning in 2010, a decline can be observed in the price of the premium with a stable trend until March of 2011. It is important to emphasize the monetary policy imposed by the Federal Reserve and the decrease of the Treasury bond (T-bill) rates, which is directly correlated to the decline of Mexican bonds (CETES) in the financial market and as a result, the impact on the cost of the premium. The following chart shows the results obtained for the upper end:

Table 8. Results obtained for the upper end presumption

\begin{tabular}{|l|r|r|r|}
\hline \multicolumn{1}{|c|}{ Periodo } & BS- Tradicional & Mercado derivados & B-S fuzificación variables \\
\hline Marzo-01-2009 & 0.21502 & 1.13200 & 0.55297 \\
\hline Junio-01-2009 & 0.42840 & 1.51000 & 1.11685 \\
\hline Marzo-01-2010 & 0.14275 & 0.90400 & 0.71424 \\
\hline Junio-01-2010 & 0.10905 & 0.36000 & 0.39065 \\
\hline Marzo-01-2011 & 0.13369 & 0.32300 & 0.64292 \\
\hline
\end{tabular}

Source: Author's own production.

By analyzing the values obtained in the upper end, it can be observed that the B-S results with fuzzification of variables get considerably close to the value recorded in the MexDer, therefore, the degree of uncertainty decreases in a significant manner. Figure 6 shows the existing spread between the two methods, it can even be seen that the curve is similar to the one during the period of June of 2009 with a downward trend in the following years. However, in March of 2011, a higher figure in the real market can be seen. This difference can be caused by the effect of volatility that directly affects the price of the option. It is important to mention that the MexDer determines the volatility in a directional basis, as it has been observed in their publications.

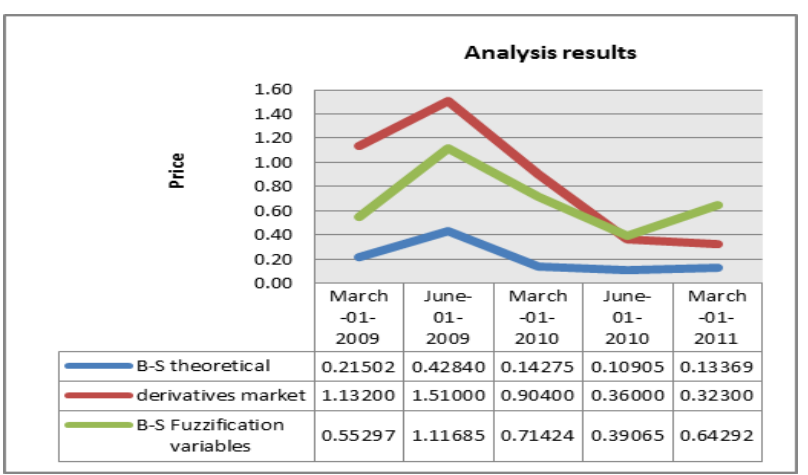

Figure 6. Comparison of exchange option pricing in the upper end.

Source: Author's own production.

The next table shows the results obtained for the lower end:

Table 9. Results obtained for the lower end presumption

\begin{tabular}{|l|c|c|c|}
\hline PERIOD & $\begin{array}{c}\text { B-S THEORE- } \\
\text { TICAL }\end{array}$ & $\begin{array}{c}\text { DERIVATIVES } \\
\text { MARKET }\end{array}$ & $\begin{array}{c}\text { B-S FUZZIFICA- } \\
\text { TION VARIA- } \\
\text { BLES }\end{array}$ \\
\hline March-01-2009 & 0.21502 & 1.13200 & 0.15172 \\
\hline June-01-2009 & 0.42840 & 1.51000 & 0.27332 \\
\hline March-01-2010 & 0.14275 & 0.90400 & 0.03808 \\
\hline June-01-2010 & 0.10905 & 0.36000 & 0.03188 \\
\hline March-01-2011 & 0.13369 & 0.32300 & 0.07419 \\
\hline
\end{tabular}

Source: Author's own production.

For the lower end, which represents the lowest expression of variable fuzziness, the B-S values with fuzzification of variable are lower than the values of the traditional B-S and the recorded values in MexDer, as the following chart shows:

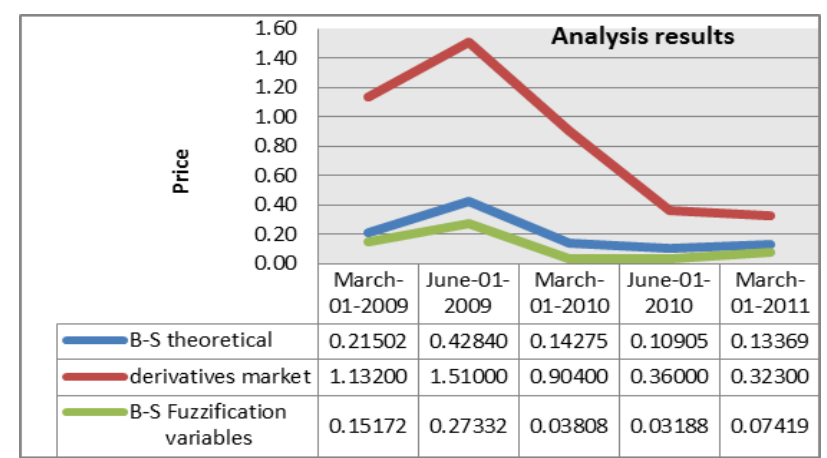

Figure 7. Comparison of an exchange option pricing in the lower end. Source: Author's own production.

In the worst case scenario, the price falls below the value obtained in the traditional B-S, however, it needs to be considered that the end events cause a great impact, but they have a low possibility of occurring.

In this case, the data obtained in the level of maximum presumption and the lower and upper ends were analyzed. Within this range, there are different levels of presumption from which the investor can choose during his or her decision-making. Based on this, it is concluded that considering the fuzzy environment of financial markets, it is 
possible to reduce the statistical bias present between MexDer and the traditional B-S model.

\section{Statistical results of the hypothesis.}

Data analysis is carried out for a significance level of 95 $\%, 90 \%$ y $80 \%$, with 8 freedom degrees and the values in the t-student table: $t_{0.05}$ error $=1.86, t_{0.10}$ error $=1.40$ $\mathrm{y} t_{0.20}$ error $=0.89$. Based on this, the values of rejection and acceptance are reject $H 0$ and accept $H 1$. According to the t-student test, the different significance levels, for each of the hypothesis based on the different degrees of presumption $(0,1)$, it can be established if there is a greater or lesser degree of accuracy in the B-S model with fuzzification of variables and the traditional B-S model, as well as to obtain a greater or lesser degree of accuracy in comparison to the spread recorded in the derivatives market in Mexico.

Table 10. Results of the hypothesis tests

\begin{tabular}{|c|c|c|c|}
\hline $\begin{array}{c}\text { Hypothesis } \\
\text { approach } \\
H_{0}: B S D \leq B S T \\
H_{I}: B S D>B S T\end{array}$ & $\begin{array}{l}\text { Test } 95 \% \text { confi- } \\
\text { dence interval, } \\
\text { acceptance or } \\
\text { rejection. } \\
\left(t_{0.05}=1.86\right)\end{array}$ & $\begin{array}{l}\text { Test } 90 \% \text { con- } \\
\text { fidence interval, } \\
\text { acceptance or } \\
\text { rejection. } \\
\left(t_{0.10}=1.40\right)\end{array}$ & $\begin{array}{l}\text { Test } 80 \% \text { con- } \\
\text { fidence interval, } \\
\text { acceptance or } \\
\text { rejection. } \\
\quad\left(t_{0.20}=0.89\right)\end{array}$ \\
\hline $\begin{array}{c}\text { Test } H_{0} \leq H_{I} \\
\text { for top }(0),(t= \\
3.55)\end{array}$ & $\begin{array}{l}\text { Rejects } H 0 \text {, so it } \\
\text { accepts } H I\end{array}$ & $\begin{array}{l}\text { Rejects } H 0 \text {, so } \\
\text { it accepts } H I\end{array}$ & $\begin{array}{l}\text { Rejects } H O \text {, so } \\
\text { it accepts } H I\end{array}$ \\
\hline $\begin{array}{c}\text { Test } H_{0} \leq H_{l} \\
\text { for maximum } \\
\text { presumption } \\
(1) \\
(t=0.95)\end{array}$ & $\begin{array}{l}\text { Accepts } H O \text {, there- } \\
\text { fore rejecting } H I\end{array}$ & $\begin{array}{l}\text { Accepts } H O \text {, } \\
\text { therefore reject- } \\
\text { ing } H I\end{array}$ & $\begin{array}{l}\text { Accepts } \mathrm{HO} \text {, } \\
\text { therefore reject- } \\
\text { ing } H \mathrm{H}\end{array}$ \\
\hline $\begin{array}{c}\text { Test } H_{0} \leq H_{l} \\
\text { for lower end } \\
(0),(t=-1.25)\end{array}$ & $\begin{array}{l}\text { Accepts } H O \text {, there- } \\
\text { fore rejecting } H I\end{array}$ & $\begin{array}{l}\text { Accepts } \mathrm{HO} \text {, } \\
\text { therefore reject- } \\
\text { ing } \mathrm{HI}\end{array}$ & $\begin{array}{l}\text { Accepts } H 0 \text {, } \\
\text { therefore reject- } \\
\text { ing } H 1\end{array}$ \\
\hline
\end{tabular}

Source: Author's own production.

\section{Conclusions}

This research confirms that the application of fuzzy logic in the exchange rate economic variables, domestic interest rate (CETES), and the foreign interest rate (T-bill) of the B-S model, present considerable advantages over the traditional B-S model. This supports the established hypothesis since the results obtained are closer to the real value of exchange option.

Based on the exchange rate data recorded by Banxico, during the period of March 2009 and March 2011, empirical calculations are carried out to determine hedge cost in a theoretical manner. The results are compared with the data of the derivatives market in Mexico (MexDer) during the same period. This comparison shows a considerable difference between the price of the option set in the market and the price set in the traditional B-S model. Hence, it can be concluded that the objective of this research was met, considering that by reducing the statistical bias pre- sent in an exchange option price; it is possible to present the investor with a range of possibilities that allow him or her to optimize the decision.

It can be established that the traditional B-S model as a measure to quantify the price of an option in MexDer, confirms the empirical evidence of the statistical bias. This can be a consequence of the effect that volatility in the financial markets has in the main variables that constitute the B-S model. This refers to the high volatility periods, particularly in the year of 2008, caused by the mortgage crisis in the United States, which affected directly the price of exchange hedge premiums in Mexico. In addition, the variation of rising interest rates records the same result. It is worth mentioning that the exogenous factor of monetary policies of central banking is an incidental element that also influences the markets in a significant manner. For this reason, it is concluded that the financial models have a certain degree of inaccuracy.

Finally, through the fuzzification of TFN (Gil-Aluja, 2004) in the economic variables of the B-S model, results with a greater accuracy in relation to real data of MexDer are empirically demonstrated. Together with the theories of PPA, balance of payments, and the Fisher approach, as well as the application of the time series econometric models: ARIMA, Winters, moving average and trend analysis, which allowed to obtain different levels of presumption between 0 and 1 , and as a result, different values were obtained in the price calculation of option exchange in the derivatives market in Mexico.

\section{References}

1. Black, F. y M. Scholes (1973). The Pricing of Options and Corporate. Journal of Political Economy, 81(3),637-654.

2. Bodie, Z. y R. Merton (1999). Finanzas. México: Prentice Hall.

3. Berkeley, George (1709). An Essay Towards a New Theory of Vision. Dublin,Ireland:

Bookfeller in Skinner-Row.

4. Boness, J. A. (1964). Elements of a Theory of Stock-Option Values. Journal of Political Economy, 72(2), 163-175.

5. Boyle, P. (1988). A Lattice Framework for Option Pricing with two State. Journal of Financial and Quantitative Analysis, 23(1), 1-12.

6. Chang, C.-C. (2001). Efficient Procedures for the Valuation and Hedging of American Currency Options with Stochastic Interest Rates. Journal of Multinational Financial Management, 11(3), 241-268.

7. Gil-Aluja, J. (1996). Towards a New Paradigm of Investment Selection in Uncertainty. Fuzzy Sets and Systems, 84(2), 187-197.

8. Gil-Aluja, J. (2004). Fuzzy Sets in the Management of Uncertainty. Germany: Springer. 
9. Gil-Lafuente, A. (2005). Fuzzy Logic in Financial Analysis. The Netherlands: Springer.

10. Harris, L. (1994). New Theories of International Trade and Exchange Rates. Journal of Development Planning, (24), 107-128.

11. Heydebrand, W. (1989). New Organizational Forms. Work and Occupations, 16(3), 323-357.

12. Hull, J., and A. White (1987). The Pricing of Options on Assets with Stochastic Volatilities. Journal of Financial, 42(2), 281-300.

13. Hull, J., and A. White (1988). The Use of the Control Variate Technique in Option Pricing. Journal of Financial and Quantitative Analysis, 23(3), 237-251.

14. Hull, J., and A. White (1996). Using Hull-White Interest Rate Trees. Journal of Derivatives, 1-17.

15. Hume, David (1752). Of the Balance of Trade. In B. Eichengreen and M. Flandreau eds, The Gold Standard in theory and history, London and New York: Routledge, 1997.

16. Jorion, P. (1996). Risk: Measuring the Risk in Value at Risk. Financial Analysis Journal, 4756.

17. Jorion, P. (2002). How Informative Are Valueat-Risk Disclosures? The Accounting Review, 77(4), 911-923.

18. Kant, Immanuel (1781). Kritik der reinen Vernunft. English tr. In Paul Guyer, Allen Wood, ed. Critique of Pure Reason, U.S.: Cambridge University Press, 2000.

19. Kaufmann, A. y Gil-Aluja, J. (1986). Introducción de la teoría de los subconjuntos borrosos a la gestión de las empresas. Santiago de Compostela: Milladoiro.

20. Kaufmann, A. y Gil Aluja, J. (1987). Técnicas operativas de gestión para el tratamiento de la incertidumbre. Barcelona: Hispano-Europea.

21. Kaufmann, A. y Gil Aluja, J. (1990). Las matemáticas del azar y de la incertidumbre: elementos básicos para su aplicación en economía. España: Centro de Estudios Ramón Areces.

22. Kosko, B. (1986). Fuzzy Entropy and Conditioning. Information Sciencies, 40, 165174.
23. Latané, H., y Rendleman, R. (1976). Standard Deviations of Stock Price Ratios Implied in Option Prices. Journal of Finance, 31, 369-381.

24. Lee C-F., G-H. Tzeng y S-Y. Wang (2005). A New Application of Fuzzy Set Theory to the Black-Scholes Option Pricing Model. Expert Systems with Applications, 330-342.

25. Mercado de Derivados Mexicano (s.f.), http://www.mexder.com.mx/MEX/paginaprincip al.html.

26. Merton, R. C. (1973). Theory of Rational Option Pricing. The Bell Journal of Economics and Management Science, 4(1), 141-183.

27. Merton, R. C. (1998). Application of OptionPricing Theory: Twenty-Five Years Later. The American Economic Review, 88(3), 323-349.

28. Miller, M. H., y F. Modigliani (1963). Dividend Policy and Market Valuation: A Reply. The Journal Business, 36(1), 116-119.

29. Peirce, Charles S. (1878). How to Make our Ideas Clear. Popular Science Monthly.

30. Samuelson, P. A. (1967). General Proof that Diversification Pays. Journal of Financial and Quantitative Analysis, 2(1), 1-13.

31. Scott, E., y A. Tucker (1989). Predicting Currency Return Volatility. Journal of Banking and Finance, 13, 839-851.

32. Zadeh, L. (1965). Fuzzy Sets. Information and Control, 8, 338-353.

33. Zadeh, L. (1968). Probability Measures of Fuzzy Events. Journal of Mathematical, Analysis and Applications, 23(2), 421-427.

34. Zadeh, L. (1972). A Fuzzy Set Theoretical Interpretation of Linguistic Hedges. Journal of Cybernetic 2(3), 4-34. 